\title{
CHANGING DYNAMICS
}

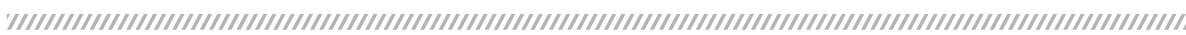

\section{Dear Reader,}

In the last few years, we've witnessed a significant leap in automotive electronics technology, primarily a result of increasingly strict regulatory demands, be it in terms of improved emissions, efficient performance, or to make vehicles safer. Further, we've seen trends such as lightweight materials, artificial intelligence, and miniaturisation, among other things, leading to rapid growth in the automotive electronics market.

From an electronics perspective, the industry has seen proliferation of innovations and new product development in the areas of powertrain, cockpits, infotronics, connectivity, communications, convergence, vehicle security system, safety and control. These, in fact, are the subjects of discussion in the third edition of our annual conference on automotive electronics - the CTO Roundtable.

A recent study released by the Global Market Insights, Inc. reports that the automotive electronics market size was valued $\$ 185.05$ bn in 2015 and is anticipated to be $\$ 352.92$ bn by 2023. The report talks about the rising automotive electronics adoption to provide safety features such as alcohol ignition interlocks, emergency call systems and mishap data recorder systems, which are expected to fuel demand growth. Offering an insight into the APAC market, the study has valued the automotive electronics market in this region at around $\$ 72.63$ bn in 2015, which is likely to grow at a CAGR of $9.1 \%$ until 2023.

Yet another study by BCC Research on automobile sensors suggests the global market should reach nearly $\$ 26.3$ bn and $\$ 43.4$ bn in 2016 and 2021 respectively, reflecting a CAGR of $10.6 \%$ over five years. Mandatory emission regulations have been cited by this research as one of the key triggers of sensor growth in the global markets. This has significance in India considering the developments currently being worked upon by the industry to meet the stringent BS VI emission norms by 2020.

The automotive technology landscape, particularly the field of electronics, has been evolving at a rapid pace. As the world moves towards automated mobility, the role of electronics is only bound to increase. We expect to learn a lot more at our conference this year. Stay tuned for the details in our June 2016 edition.
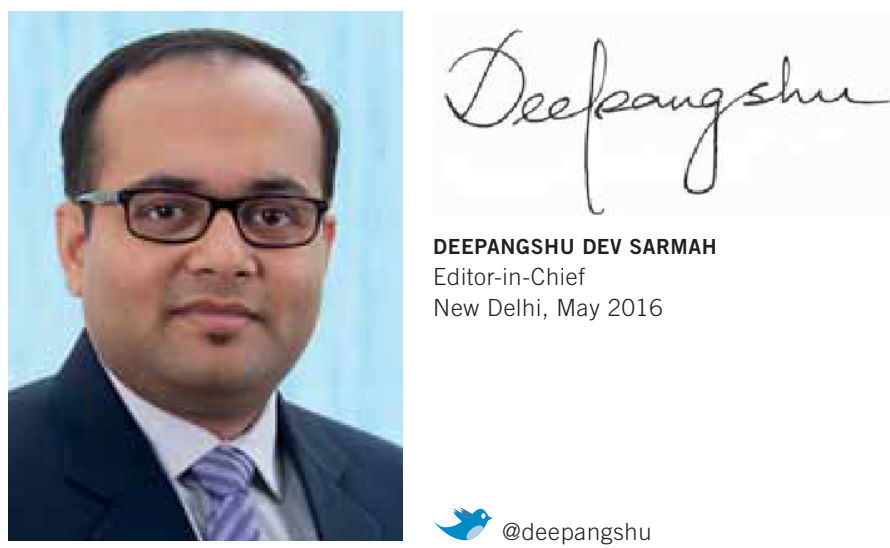

DEEPANGSHU DEV SARMAH

Editor-in-Chief

New Delhi, May 2016 